\title{
Experiences from a collaborative project on the prevention of disability in leprosy patients in Shandong Province, the People's Republic of China
}

\author{
CHEN SHUMIN, ZHANG LIN, WANG ZHAOZI, \\ ZHOU JIYANG, LIU YINGWEI \& MAO CHENGYU \\ Shandong Provincial Institute of Dermatology and Venereology, \\ 57 Jiyan Lu, Jinan, Shandong, People's Republic of China 250022
}

\author{
Accepted for publication 17 July 2001
}

\begin{abstract}
Summary Shandong Province (present population 89 million) in the People's Republic of China established a leprosy control programme in 1955. Between that year and the end of 1999, allowing for death and migration, the cumulative number of cases registered was 53,618, including 120 cases on multiple drug therapy (MDT) and 18,248 who had completed satisfactory courses of dapsone monotherapy and/or MDT. Of this latter group, 9500 cases (52\%) suffered from visible disabilities (grade 2 of the WHO classification). Prevalence and incidence rates of leprosy have decreased dramatically since 1955 and, on average, only 50-70 new cases are now being detected annually in the entire province. Leprosy is thus no longer a public health problem, but the existence of such a large number of patients with grade 2 disabilities is clearly a matter of serious concern. This paper describes a pilot project to investigate the potential of health personnel in the leprosy programme and the dermatology and sexually transmitted diseases services to (a) prevent deterioration of existing disabilities in ex-patients through self-care and (b) prevent new neuritis in patients on MDT through early detection and the use of steroids.
\end{abstract}

\section{Introduction}

Shandong Province (present population 89 million), in the People's Republic of China, is situated in the eastern, coastal part of the country. It has 17 prefectures and municipalities and 135 countries, with $80 \%$ of the population living in rural areas. With 573 people per square kilometre, it is one of the most densely populated provinces in the whole country. ${ }^{1}$

A leprosy control programme was established in 1955. Between that year and the end of 1999, allowing for deaths and migration, the cumulative number of cases registered was 53,618 , including 120 cases on multiple drug therapy (MDT), as recommended by the World Health Organisation (WHO) and 18,248 who had completed satisfactory courses of dapsone monotherapy and/or MDT. Of the latter group, 9500 (52\%) suffered from visible disabilities 
(grade 2 on the WHO classification). The prevalence rate of leprosy in Shandong decreased from 0.4 per 1000 of the population in 1967 to 0.0037 per 1000 in 1994 and the yearly detection rate decreased from 0.1 per 1000 in the period $1955-1959$ to 0.066 per 1000 in 1990-1994. On average, only 50-70 new cases have been detected yearly in the entire province during the past decade. Leprosy is thus no longer a public health problem, but the presence of nearly 20,000 ex-patients with grade 2 disability is clearly a matter of serious concern.

Further details of the epidemiological situation in this province from 1955 to 1983 have already been published. ${ }^{2}$ This paper describes a pilot project, in collaboration with the The Leprosy Mission International (TLMI) and the Ministry of Health, China, ${ }^{3}$ to investigate the potential of health personnel working with the leprosy control programme and the dermatology and sexually transmitted diseases services to (a) prevent deterioration of existing disabilities in ex-patients through self-care and (b) prevent new neuritis in patients on MDT through early detection and the use of steroids.

\section{Materials and methods}

The project aimed to:

1. Improve and complete the rehabilitation management and supervision system in preparation for a future provincial project.

2. Monitor and treat any new neuritis cases with a standard steroid regimen.

3. Prevent or control the occurrence of new disability and deformity over 3 years as follows:

a. Prevent any further loss of sensation or strength after diagnosis and to reverse loss occurring within 6 months prior to diagnosis, by improving early detection and treatment of neuritis.

b. Reduce the prevalence of wounds and open cracks by $80 \%$ and control the incidence of new re-occurrence to below $5 \%$ for outpatients and below $2 \%$ for inpatients.

c. Prevent any increase in vision loss, joint stiffness and bone loss following nerve dysfunction.

4. Minimize the social and functional effect of the above impairments on the lives of patients and their families.

5. Provide protective footwear for more than $80 \%$ of cases with insensitive feet in the pilot areas within 1 year of starting the project.

6. Enable diagnosed cases in the project areas to be trained in self-care and to achieve proficiency in $60 \%$ of them by the end of the project.

Project approval was granted by the Provincial Bureau of Health, with emphasis on the following principles:

1. Main attention and priority to be given to patients under 60 years of age.

2. Strong government commitment and community participation.

3. A combined approach between the specialized leprosy services and the primary health care services.

4. Strengthening of empowerment of disabled patients and their families.

\section{IMPLEMENTATION}

After an initial national meeting, contracts were signed between the director of the Provincial Bureau of Health and the directors of the bureau of health in the six selected pilot counties, in 
order to strengthen leadership and ensure allocation of funds on time. This was followed by a provincial meeting to motivate and ensure the participation of health staff in general health services at different levels. The main activities in the implementation of the project were as follows:

\section{Training}

In general, training involved affected persons, leprosy doctors, village doctors and other paramedical health workers in the main principles of disability management, focusing on simple measures that can be carried out in the home and field situation. At the beginning of the project, a workshop on prevention of disability (POD) in terms of technical and management aspects was held by the national leprosy control centre (CLC) and experts from TLMI for leprosy control managers in charge of the project at the provincial level, followed by a similar training course at provincial level. Leprosy workers in charge of the project at county level participated in the workshop. Paramedical health workers at township level and village doctors, in turn, were trained in a 1-day course organized by local health authorities at county level.

\section{Technical aspects of the project in the field}

General description of activities. According to the guidelines of the project and after training of health staff at different levels, project staff in leprosy control stations visited the homes of the patients. During the visits, primary and secondary impairments of the patients were assessed and recorded on project forms (information at baseline). Health education on self-care was then given according to each patient's individual problems, and patients were told how to take care of their hands and feet in their everyday lives, with regard to numbness and deformity. Care of the eye and management of cracks and wounds in the hands and feet at home was discussed and demonstrated. Some drugs such as eye ointment and drops, materials such as bandages, scalpels, tapes and dark eye glasses, were provided and replaced according to needs. The persons involved were also told to consult rural doctors or paramedical doctors in township hospitals for any problems they could not deal with at home.

Methods of testing muscle strength and sensation of hands and feet. The methods of testing muscle strength and sensation of hands and feet were the same as those used in the project state 1 , as already described. ${ }^{3,4}$ Briefly, a three-scale system was used in testing muscle strength dominated by ulnar nerve, radial nerve, medial nerve and popliteal nerve, respectively (normal $=0$, limitation of movement range $=1$, reduction of resistance $=2$, paralysed $=3$ ). Ten points on each hand or foot were tested with a ball-pen. The results of the tests were marked in a standard chart at baseline and during follow-up for comparison.

\section{Supervision and evaluation}

The project had full supervision from provincial to county level, in a scheduled manner (twice a year), with or without assistance of experts from CLC and TLMI. Ongoing training was conducted during supervision by the project management team, consisting of experts from TLMI, CLC and Shandong Provincial Institute of Dermatology and Venereology evaluated the results of the project in three of the six pilot counties. 
Table 1. Baseline profile of 1132 cases affected by leprosy, by sex, leprosy type, age group and residence in six pilot counties in Shandong

\begin{tabular}{|c|c|c|c|c|c|c|c|c|}
\hline \multirow[b]{2}{*}{ Residence } & \multicolumn{2}{|l|}{ Sex } & \multicolumn{3}{|c|}{ Leprosy type } & \multicolumn{3}{|c|}{ Age group } \\
\hline & Male & Female & MB & PB & $<40$ & $<50$ & $<60$ & $>60$ \\
\hline Out-patients & 854 & 213 & 427 & 640 & 33 & 130 & 422 & 482 \\
\hline In-patients & 64 & 1 & 42 & 23 & 4 & 3 & 15 & 43 \\
\hline Total & 918 & 214 & 469 & 663 & 37 & 133 & 437 & 525 \\
\hline
\end{tabular}

\section{Results}

One thousand and eighty-six of the 1132 cases involved in the project form a cohort of persons both at project start and at the latest review ( 32 had died and 14 were lost). Table 1 illustrates the sex, leprosy type, residence and decades of birth of persons in this group. The primary nerve function impairment among 1086 leprosy cases at the start of the project is given in Figure 1. One of the objectives of the project had been to make patients competent in self-care, but due to lack of a clear definition and proper indicators, this proved difficult to measure. Similarly, it was difficult to assess the social effect of the project on lives of the leprosy-affected persons and their families.

Regarding nerve function impairment (NFI) monitoring in the group of active cases, three out of 54 cases on MDT were identified as having neuritis. After 6 months treatment with a standard regimen of steroids, one of the three was considered as partly recovered and the other two as showing no change. The number in this cohort of patients was obviously too small to be significant. Figure 2 illustrates the changes in secondary impairments over time in the period of the 3-year project.

Vision loss and bone loss in this group of patients were 399 (160 eyes and 239 bones, respectively). Since vision loss (due to a variety of inflammatory conditions) and bone loss did not show much change, they are not illustrated here in detail.

In summary, the main outcome with regard to secondary impairments included the following (Figure 2):

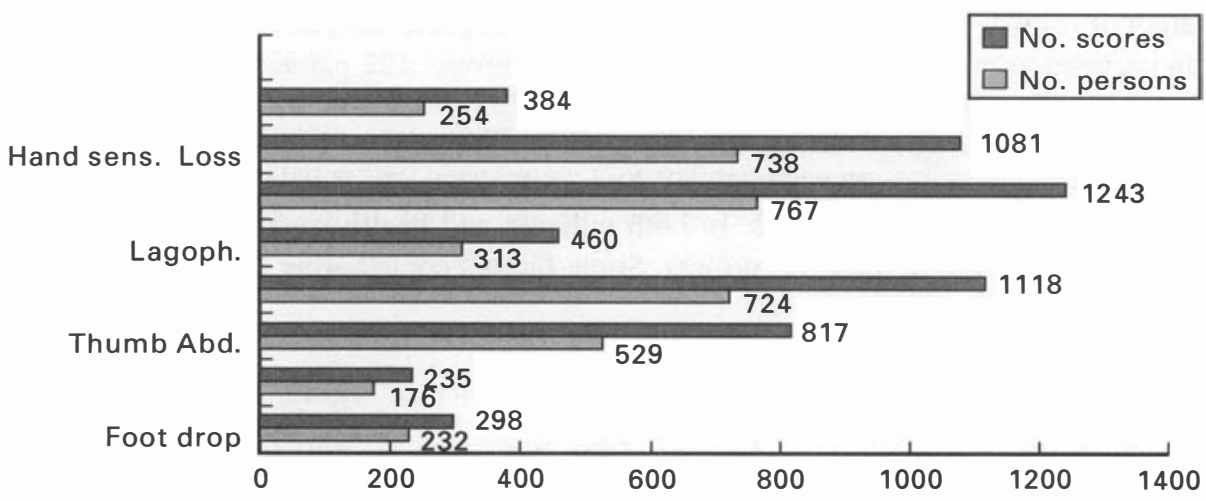

Figure 1. Primary nerve function impairment among 1086 leprosy cases at the start of the project. 


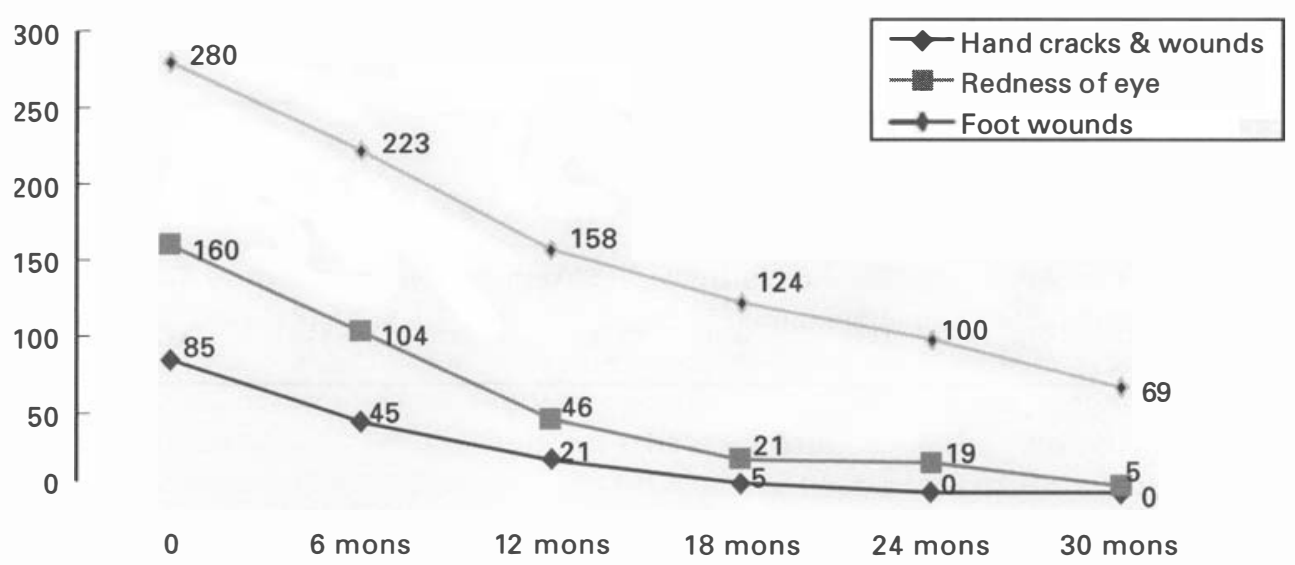

Figure 2. Changes in secondary impairments over time among 1086 leprosy cases in the 3-year period of the project.

1. A $97 \%$ reduction in number of patients with redness of the eyes, with loss of corneal sensation or lagophthalmos.

2. A $94 \%$ reduction in number of persons having open cracks and wounds on their hands.

3. A $75 \%$ reduction in number of sole wounds in feet with sensory loss.

\section{Discussion}

With regard to the early detection and treatment of neuritis with steroids, only 54 active cases were monitored in the period of the project and only three of them identified as having new neuritis. After treatment with steroids for 6 months, one patient with obvious nerve pain and sensory loss in the sole completely recovered, but there was no change in the other two. Obviously, the number of cases with new neuritis was too small to make any assessment. The results of treatment of neuritis with steroids nationwide, however, have been impressive, and comparable to studies in other parts of the world. ${ }^{5}$

Protective footwear, even sports shoes sold in the market, has a definite role in the protection of feet with sensation loss, ${ }^{6,7}$ if used properly. Five hundred and six cases received footwear in this group. Due to the lack of a control group, however, and the short duration of the study, it is difficult to assess the role of footwear in protection of feet with sensation loss and in prevention of relapses of foot wounds. In this group, 122 pateients with plantar ulcers achieved healing within 1 year of the project, and $75 \%$ reduction within the 3 -year period, which is more encouraging than results reported in the literature from other countries.

The most impressive achievement was the remarkable reduction in number of secondary impairments, as shown in Figure 2. In both patients and health staff, this led to a marked increase of confidence in the POD project. Some factors contributing to this achievement of the project are outlined below.

STRONG GOVERNMENT COMMITMENT AND INVOLVEMENT OF GENERAL HEALTH SERVICES

- A medical officer (usually vice-director of the Bureau of Health) was appointed to be in charge of the project at three levels (province, prefecture and county). This made coordination and supervision much easier. 
- A series of documents on the implementation of the project were issued at the above three levels.

- Contributory funding was allocated on time.

\section{EMPHASIS ON TRAINING}

Since a POD project is totally different from a programme aiming to control the spread of the disease, including implementation of MDT, training of staff involved at different levels, not only in workshops but also in ongoing POD activities, is crucial to success. During the project period, considerable effort was made not only for training in knowledge and skills, but also to develop correct attitudes towards leprosy-affected persons. In this context, foreign experts set a good example for our staff both in the training courses and during field visits.

\section{AN ACTION LEARNING MANAGEMENT APPROACH}

The 'action learning' management approach encourages involvement of teams of people, in this case leprosy staff, so that they focus on the same or similar objectives, meeting together periodically to encourage and leam from each other and to exchange ideas and reports regarding progress.

SOME LESSONS LEARNT FROM THE PROJECT

\section{Planning}

Affected persons and their family members, integrated programme staff, and the project managers might be more closely involved in all stages of planning and implementation of a POD project of this kind.

\section{Case selection priorities need to be clarified}

Several problems were encountered with regard to selection of project cases. This was partly because the selection guidelines were insufficiently clear and partly because numbers to be involved were based on WHO disability grading alone. The grading does not give sufficient detail for POD planning purposes. It is important that future surveys for this purpose provide more information regarding the type and extent of impairment. Informal questionnaires may be used to identify the patients' felt needs and the relationship between impairment and these needs.

\section{Communication skills}

There are many good reasons why a client may not implement advice given. For example, he/she may not be convinced of the reasoning behind the advice, or may lack access to ongoing supplies of materials or may find it impractical to follow the advice in a given situation. Ongoing training is needed so that staff are equipped with listening, problem identification and problem-solving skills, and do not advise too much and listen too little. 


\section{Sustainability}

Sustainability of the project is the key for the benefit of patients in the long run, and one of the main objectives of this project. On its completion, it is clearly essential that patients have the motivation, knowledge and ability to continue self-care and other activities on a long-term, often indefinite basis. Unfortunately, it has not been possible to address this issue adequately so far in this province, and there is a need to consider an overall plan, perhaps combining selfcare with community-based rehabilitation, so that the full potential of the approach described in this paper becomes truly sustainable.

\section{CONCLUSIONS}

1. Although the project described here did not succeed in all its initial objectives, it confirmed, to a remarkable degree, previous reports ${ }^{3,5}$ of the potential of health staff to prevent and reverse secondary impairments in patients affected by leprosy, notably red eyes, cracks and wounds of the hands and feet.

2. The results achieved so far should not be regarded as short-term or dependent on external aid and encouragement, but rather become accepted practice by the patients and staff concerned, with a high degree of sustainability.

3. The good results recorded were evident to both health staff and patients and contributed greatly to increasing confidence in the value of the methods used. It is intended that they will form the basis for POD and rehabilitation acitivities in the entire province in the future.

\section{Acknowledgements}

We wish to record our thanks to the Leprosy Mission International (TLMI) and other donors for their financial support for this 3-year pilot project. We also thank Miss Jean Watson, Miss Angelika Piefer and others involved in the project for their technical guidance and care for our patients during and after the project in Shandong Province. We are extremely grateful to all the staff involved in this project for their hard work and kindness to so many patients disabled by this disease.

\section{References}

${ }^{1}$ Chen S. Options for leprosy control programme in Shandong Province, China. Thesis (Master of Public Health), Royal Tropical Institute, Amsterdam, The Netherlands, 1995.

${ }^{2}$ Li H, Pan Y, Wang Y. Leprosy control in Shandong Province, China 1955-1983; some epidemiological features. Int J Lepr, 1985; 53: 79-85.

3 Smith WCS, Zhang GC, Zheng TS et al. Prevention of impairment in leprosy: results from a collaborative project in China. Int J Lepr, 1995; 63: 507-517.

4 Watson JM. Disability control in a leprosy control programme. Lepr Rev, 1989; 60: 169-177.

5 Jiang J, Watson JM, Zhang GC, Wei X. A field trial of detection and treatment of nerve function impairment in leprosy-report from national POD pilot project. Lepr Rev, 1998; 69: 367-375.

6 Birke JA, Foto JG, Deepak S et al. Measurement of pressure walking in footwear used in leprosy. Lepr Rev, 1994; 65: $262-271$.

7 Srinivasan H. Deformity and disability-unfinished agenda in leprosy work. Lepr Rev, 1995; 66: 193-200. 